\title{
Caring for the Sick Newborns in Nurseries in a Developing Setting: Evaluation of the Psychosocial Burden on Caregivers
}

\author{
Uchenna Ekwochi, Isaac N. Asinobi, Christian Ifediora ${ }^{1}$, Ikenna K. Ndu, Stanley Kenechukwu Onah ${ }^{2}$, \\ Ogechukwu F. Amadi, Chidiebere D. I. Osuorah ${ }^{3}$
}

Department of Paediatrics, Enugu State University of Science and Technology, Enugu, Enugu State,

${ }^{2}$ Department of Paediatrics, Nnamdi Azikiwe University Teaching Hospital Nnewi, Nnewi, Anambra State, Nigeria, ${ }^{1}$ Department of Family Medicine, Griffiths University Medical School, Gold Coast, Australia, ${ }^{3}$ Child Survival Unit, Medical Research Council UK, The Gambia Unit, Fajara, The Gambia

Received: $28^{\text {th }}$ August, 2019 Revision: $21^{\text {st }}$ October, 2019 Accepted: $24^{\text {th }}$ November, 2019 Publication: $29^{\text {th }}$ January, 2020
Background: Caring for the sick newborn in a developing setting is very challenging. Apart from the medical facilities and expertise of the medical team, other factors such as the ability of the caregiver to adapt to the financial, economic, and psychosocial demands associated with the illness process also determine survival. This study explored the psychosocial burden of caregivers and its related factors in a developing setting. Methodology: This cross-sectional and analytical study was carried out prospectively over an 18-month period at the Special Care Baby Unit of Enugu State University Teaching Hospital. Caregivers who consented were consecutively enrolled. IBM SPSS version 20 was used for data analysis and statistical significance was set at $P \leq 0.05$. Results: There was a wide range of psychosocial burden experienced by caregivers during the admission period of the sick newborn. The most common encountered psychological burden included catastrophic economic sacrifice because of baby's ill health (40.0\%), worry about not giving the baby the best care (39.7\%), feeling of loneliness and isolation $(39.5 \%)$, tiredness and constant feeling of been worn out $(34.6 \%)$, and limitation on one's own social life (32.8\%). Several factors such as place of birth, educational level of the caregiver, previous preterm baby in the family, length of stay in hospital, number of additional children to look after, and the birth weight of the baby were predictive factors of degree of psychosocial burden faced by caregivers. Conclusion: Caregivers of sick newborn experience significant levels of psychological burden with considerate impact on the care and outcome of newborns. Comprehensive sick newborn care should envisage and incorporate the management of different domains of stressors among caregivers.

KEYWORID: Caregiver, developing setting, psychosocial burden, sick newborn

\section{INTRODUCTION}

Childbearing and care are quite demanding. It is even more challenging, when the newborn becomes sick and needs to be admitted in hospital. It is well documented that the infancy period is the most vulnerable period in life with the highest risk of dying in their $1^{\text {st }}$ month of life. ${ }^{[1]}$ Clinicians and more importantly parents of sick newborns are often faced with lots of challenges and uncertainties, knowing fully well their limited chance of survival which stems from combination of factors. ${ }^{[2]}$ Apart from the higher risk of death in sick newborns in resource-poor settings, the medical

\begin{tabular}{|l|l|}
\hline \multicolumn{2}{|c|}{ Access this article online } \\
\hline Quick Response Code: & Website: \\
\hline
\end{tabular}

expenditure which is usually out-of-pocket payment is usually catastrophic on family livelihood.$^{[3]}$ Furthermore, the long period of hospital stay for sick newborns, especially when premature, adds to the physical, economic, and psychosocial burden on caregivers. Therefore, it is fair to hypothesize that the survival of sick newborns in a resource-limited setting such as ours

Address for correspondence: Dr. Chidiebere D. I. Osuorah, Child Survival Unit, Medical Research Council UK, The Gambia Unit, Fajara, The Gambia. E-mail: chidi.osuorah@yahoo.com

This is an open access article distributed under the terms of the Creative Commons Attribution-NonCommercial-ShareAlike 4.0 License, which allows others to remix, tweak, and build upon the work non-commercially, as long as the author is credited and the new creations are licensed under the identical terms.

For reprints contact: reprints@medknow.com

How to cite this article: Ekwochi U, Asinobi IN, Ifediora C, Ndu IK, Onah SK, Amadi OF, et al. Caring for the sick newborns in nurseries in a developing setting: Evaluation of the psychosocial burden on caregivers. J Clin Neonatol 2020;9:69-76. 
is dependent not only on medical facilities available but also on the ability of parents and/or caregiver to adapt to the financial, economic, and psychosocial demands associated with the management of the sick newborns. This study sought to explore the various dimensions of psychosocial burdens and the determinants of these burdens among caregivers with newborns admitted to the Special Care Baby Unit (SCBU) of Enugu State University Teaching Hospital (ESUTH). It is believed that gauging and understanding the extent of these burdens will serve as a guide for health-care administrators and medical management team in their reevaluation of the expectations placed on caregivers of sick newborns in developing communities such as Enugu.

\section{Methodologi}

\section{The study designs}

This was a cross-sectional and analytical questionnaire-based survey carried out at the SCBU of ESUTH over an 18-month period (June 2017-November 2018). The SCBU at ESUTH serves as a referral center for specialized neonatal care for babies delivered within the hospital and those referred to it from low-level health-care facilities in Enugu and neighboring states. The center has the capacity to cater for 360-400 sick babies in a year. The unit is staffed by neonatologists, resident doctors training to specialize in pediatrics, and trained pediatric nurses. The setting in the SCBU provides a breastfeeding corner for mothers and caregivers where they stay to curdle, breastfeed, and offer kangaroo mother care (KMC) to their babies. There is also a mothers' room which accommodates only a limited number of mothers; hence, most mothers and/or caregivers are forced to stay outside the SCBU when their baby is on admission. Most caregivers usually have to shuttle between their homes and the hospital to provide psychosocial care and supplies needed for the care of their sick baby.

\section{Recruitment of the study participants}

Participants in this study were primary caregivers defined for the purpose of this study as anyone directly responsible for the care of the baby when on admission in SCBU. After obtaining informed consent, participants were interviewed using structured questionnaires administered by trained research assistants and/or self-administered depending on the reading ability of participants. The questionnaires were generally administered at the point of discharge, referral, or death of the respondent's sick child. This was strategically timed, so that at the point of questioning, the respondents would have gone through the hurdles associated with the care of a hospitalized infant in the SCBU. Respondents who lost their babies and agreed to participate in the study were often offered counseling before administering the questionnaire, knowing fully well potential biases can be introduced during data collection.

\section{Data collection}

The first section of the questionnaire inquired about the basic personal data of caregivers which included occupation, highest educational level, number of people in their household, previous preterm birth, and presence of disabled child in the home. Some vital indices of the sick baby were also collected. These included sex, age at presentation, birth weight, duration of admission, and any form of support enjoyed by the caregiver during their baby's admission. The second section of the questionnaire assessed the psychosocial burden encountered by caregivers when caring for their sick newborn. This was done through a set of validated qualitative questions adapted from a similar study from Zarit et al. The responses to these questions were based on the 4-point Likert scale which ranged from not at all, seldom, sometimes, and often.

\section{Data entry and analysis}

All analyses were performed with IBM $^{\circledR}$ SPSS version 25.0 (SPSS Inc., Chicago, IL, USA). Descriptive and inferential analyses were used to explore the responses. The first 17 questions on the questionnaire were presented using descriptive analysis, with results displayed as numbers and percentages. Where feasible, the results were grouped in two or three categories to allow better understanding.

Questions 18-39 were presented using a descriptive analysis. First, all responses were presented as on the questionnaire, showing the 4-point Likert scale. Afterward, the responses were dichotomized into "No" and "Yes." All responses of "Not at all" or "Seldom" were categorized as "No," whereas responses of "Sometimes" and "Often" were grouped as "Yes." Apart from allowing for easy understanding of the responses, this also made it possible to apply the results in the binary logistic regression (BLR) used for the inferential analysis.

The inferential analysis was used to identify statistical associations, and a 2-staged BLR method was used. The 22 individual items of caregiver burdens (questions 18-39 in the questionnaire) formed the "independent or predictor variables," whereas a total of 14 sociodemographic variables formed the "dependent or outcome variables."

For the first stage, all 22 independent variables were individually analyzed against each dependent variable, and those with significant probability $(P)$ values were identified. All significant variables for each dependent 
variable were grouped together and analyzed together in the Stage 2 of the analysis. This way, an adjustment was made for the other significant variables. Only the significant results from the Stage 1 are presented, but, for the Stage 2, all results are presented.

For each inferential analysis, the odds ratio (OR) and confidence interval (CI) were generated, along with the $P$ values. Associations were deemed to be significant if $P \leq 0.05$.

\section{Ethical considerations}

Ethical clearance and permission for the research was obtained from the Ethical Committee of ESUTH, Parklane, Enugu.

\section{Resultis}

\section{Demographics of the study respondents}

The basic sociodemographics of the respondents are summarized in Table 1. A total of 134 caregivers responded, of which $78 \quad(58.2 \%)$ were male. Most (57.1\%) of the babies in the Newborn Unit were born within ESUTH Teaching Hospital, whereas the rest were born outside, but admitted to the unit afterward. About $28.1 \%$ of the babies in the unit were low birth weight $(<2.5 \mathrm{~kg})$ at birth. More than half $(57.9 \%)$ of the babies stayed on admission for 7 days or less, whereas the remainder (42.1) stayed for longer days.

Most of the newborns were born to families with one other child or none $(51.8 \%)$, whereas $17.3 \%$ of the caregivers reported having 4 or more other children in their household. When the total number of people in the households was considered (including adults), only $32.0 \%$ were from small families (3 or less), with $39.1 \%$ and $28.9 \%$ being from medium (4-5) and large (6 or more) families, respectively.

A large majority of the babies were from homes with no previous preterm babies $(85.4 \%)$ or disabled babies (97.6\%), and among their parents, nearly 9 out of every 10 were educated to senior secondary school levels (high schools) or higher. Only about a quarter of the mothers are not in any form of employment, with approximately $74 \%$ engaging in one kind of money-making job or another. About $37.5 \%$ received support when their babies were on admission (as cash, toiletries, medications, and payment of their hospital bills).

\section{The caregiver burdens}

Table 2 depicts the full results of the responses to the 22-item questions that explored burdens in dichotomous variable. As shown, the levels of burden ranged from $3.9 \%$ (Item 22) to $40.0 \%$ (Item 18), which were generally low across the 22 items, with majority of
Table 1: Demographics of sick newborns on admission in the Newborn Unit of Enugu State University Teaching Hospital

\begin{tabular}{|c|c|c|}
\hline Patient characteristics & Variables & $n(\%)$ \\
\hline \multirow[t]{2}{*}{ Gender $(n=134)$} & Male & $78(58.2)$ \\
\hline & Female & $56(41.8)$ \\
\hline \multirow[t]{2}{*}{ Place of birth $(n=134)$} & Inborn & $72(57.1)$ \\
\hline & Outborn & $54(42.9)$ \\
\hline \multirow[t]{5}{*}{ Birth weight $(\mathrm{kg})(n=121)$} & $\leq 2.49$ & $34(28.1)$ \\
\hline & $\geq 2.50$ & 87 (71.9) \\
\hline & Mean & 2.9 \\
\hline & Range & $1.20-5.00$ \\
\hline & $\mathrm{SD}$ & 0.87 \\
\hline \multirow{6}{*}{$\begin{array}{l}\text { Number of other children } \\
\text { in family }(n=110)\end{array}$} & $\leq 1$ (small) & $57(51.8)$ \\
\hline & 1-3 (average) & $34(30.9)$ \\
\hline & $\geq 4$ (large) & $19(17.3)$ \\
\hline & Mean & 2.03 \\
\hline & Range & $1-7$ \\
\hline & $\mathrm{SD}$ & 1.36 \\
\hline \multirow{6}{*}{$\begin{array}{l}\text { Total number of people in } \\
\text { family }(n=128)\end{array}$} & $\leq 3($ small $)$ & $41(32.0)$ \\
\hline & 4-5 (medium) & $50(39.1)$ \\
\hline & $\geq 6$ (large) & $37(28.9)$ \\
\hline & Mean & 4.73 \\
\hline & Range & $2-18$ \\
\hline & SD & 2.00 \\
\hline \multirow{5}{*}{$\begin{array}{l}\text { Days stayed on hospital } \\
\text { admission (days) }(n=130)\end{array}$} & $\leq 7$ & $73(57.9)$ \\
\hline & $>7$ & $57(42.1)$ \\
\hline & Mean & 9.98 \\
\hline & Range & $1-43$ \\
\hline & SD & 8.25 \\
\hline \multirow{2}{*}{$\begin{array}{l}\text { Previous preterm } \\
\text { babies }(n=120)\end{array}$} & Yes & $19(14.6)$ \\
\hline & No & $111(85.4)$ \\
\hline \multirow{2}{*}{$\begin{array}{l}\text { Previous disabled } \\
\text { babies }(n=132)\end{array}$} & No & $121(97.6)$ \\
\hline & Yes & $3(2.4)$ \\
\hline \multirow{2}{*}{$\begin{array}{l}\text { Father's highest } \\
\text { educational level }(n=118)\end{array}$} & SSCE or higher & $102(86.4)$ \\
\hline & Less than SSCE & $16(13.6)$ \\
\hline \multirow{2}{*}{$\begin{array}{l}\text { Mother's highest } \\
\text { educational level }(n=126)\end{array}$} & SSCE or higher & $110(87.3)$ \\
\hline & Less than SSCE & $16(12.7)$ \\
\hline \multirow{2}{*}{$\begin{array}{l}\text { Mother's employment } \\
\text { status }(n=115)\end{array}$} & Employed & 85 (73.9) \\
\hline & Unemployed & $30(26.1)$ \\
\hline \multirow{2}{*}{$\begin{array}{l}\text { Special support } \\
\text { received }(n=112)\end{array}$} & Yes & $42(37.5)$ \\
\hline & No & $70(62.5)$ \\
\hline
\end{tabular}

$\overline{\text { SSCE - Senior secondary school certificate examination; }}$ $\mathrm{SD}$ - Standard deviation

the responses being "Not at all." The least reports of burdens (Sometimes of Often) were on "avoiding invitations to nonfamily members (Item 22 with $3.9 \%$ )," "an expectation that the caregiver would have achieved more (Item 21 with 6.3\%)," and "the neighborhood making care of baby troublesome (Item 17 with $6.9 \%$ )." The highest burdens were reported on "an experience of economic sacrifice because of baby (Item 18 with $40.0 \%$," "worry about not properly caring for the baby (Item 15 with 39.7\%)," and "a feeling of loneliness and isolation (Item 2 with 39.5\%)." 
Table 2: Binary categorization of the various psychosocial burdens experienced by caregivers of sick babies in the Newborn Unit of Enugu State University Teaching Hospital

\begin{tabular}{|c|c|c|c|c|}
\hline \multirow[t]{2}{*}{ Nature of caregiver burden } & \multicolumn{4}{|c|}{ Response* } \\
\hline & No & Yes & Total & Mean $^{\dagger}$ \\
\hline 1. Feels tired and worn-out because of the baby's problem? & $85(65.4)$ & $45(34.6)$ & 130 & 1.78 \\
\hline 2. Feels lonely and isolated because of the baby's problem? & $78(60.5)$ & $51(39.5)$ & 129 & 1.93 \\
\hline 3. Must shoulder many responsibilities for the baby's welfare? & $82(66.7)$ & $41(33.3)$ & 123 & 1.84 \\
\hline 4. Feels like running away from the entire situation? & $116(90.6)$ & $12(9.4)$ & 128 & 1.23 \\
\hline 5. Facing practical problems in the care of baby that may be difficult to solve? & $105(81.4)$ & $24(18.6)$ & 129 & 1.51 \\
\hline 6. Feels offended and angry with the baby's health condition? & $98(77.2)$ & $29(22.8)$ & 127 & 1.56 \\
\hline 7. Own health has suffered because of taking care of the baby? & $103(81.7)$ & $23(18.3)$ & 126 & 1.45 \\
\hline 8. Own social life (e.g., with family and friends) has lessened due to the baby? & $82(67.2)$ & $40(32.8)$ & 122 & 1.81 \\
\hline 9. Physical environment makes caring for the baby troublesome? & $96(78.0)$ & $27(22.0)$ & 123 & 1.53 \\
\hline 10. Feels tied down by baby's problem? & $104(82.5)$ & $22(17.5)$ & 126 & 1.43 \\
\hline 11. Feels embarrassed by the baby's health status or size/weight? & $103(83.1)$ & $21(16.9)$ & 124 & 1.42 \\
\hline 12. Baby's problem prevented you from own ambitions at this stage of own life? & $91(74.0)$ & $32(26.0)$ & 123 & 1.63 \\
\hline 13. Finds it physically tiring to take care of your baby? & $107(85.6)$ & $18(14.4)$ & 125 & 1.38 \\
\hline 14. Spends much time on baby and insufficient time for self? & $101(80.8)$ & $24(19.2)$ & 125 & 1.54 \\
\hline 15. Worry about not taking not properly caring for the baby? & $76(60.3)$ & $50(39.7)$ & 126 & 1.93 \\
\hline 17. Sometimes ashamed of your baby's weight or size? & $109(84.5)$ & $20(15.5)$ & 129 & 1.36 \\
\hline 18. Anything in home neighbourhood making care of the baby troublesome? & $122(93.1)$ & $9(6.9)$ & 131 & 1.18 \\
\hline 19. Experienced economic sacrifice because of baby care? & $78(60.0)$ & $52(40.0)$ & 130 & 1.94 \\
\hline 20. Finds it mentally tiring to take care of the baby? & $115(90.6)$ & $12(9.4)$ & 127 & 1.24 \\
\hline 21. Feeling that life has been unfair due to having the baby? & $119(93.0)$ & $9(7.0)$ & 128 & 1.16 \\
\hline 22. Expected life would be different than it is at your age by achieving more, if not for the baby? & $120(93.8)$ & $8(6.3)$ & 128 & 1.16 \\
\hline 23. Avoiding the invitation of acquaintances to family home because of the baby's problem? & $122(96.1)$ & $5(3.9)$ & 127 & 1.10 \\
\hline
\end{tabular}

*No response signifies not at all or seldom; Yes, signifies sometimes or often; $\uparrow$ Range of mean is from 1-4 where $1=$ Not at all $4=0$ Often

\section{Associations}

Table 3 shows the results of the 2-staged BLR analysis. Of the 14 dependent variables included in the analysis, 8 had significant associations with at least 1 of the 22 independent variables (caregiver burden parameters). Unadjusted, the "Place of Birth" was associated with 4 out of the 22 independent variables. Caregivers of "Inborn" babies in newborn units were less likely to report "feeling offended with baby's condition" (OR: 0.29; CI: $0.12-0.71 ; P=0.01$ ), "feeling tied down by the baby's problem (OR: 0.31 ; CI: $0.11-0.82$; $P=0.02$ ), "feeling of baby's problem preventing own ambition" (OR: 0.30; CI: 0.13-0.70; $P=0.01$ ), and a "feeling that life has been unfair due to having the baby" (OR: 0.19; CI: 0.04-0.93; $P=0.04$ ). However, when adjusted for all the other significant variables, only the "feeling that life has been unfair due to having the baby" (OR: 0.37; CI: 0.14-0.98; $P=0.05$ ) remained statistically significant. Parental educational attainment of senior secondary school certificate examination (SSCE) or higher was also associated with a lesser likelihood to "worry about not taking not properly caring for the baby" for both fathers (OR: $0.21 ; \mathrm{CI}: 0.06-0.78 ; P=0.02$ ) and mothers (OR: $0.12 ;$ CI: $0.03-0.45 ; P=0.002$ ). It should be noted that "father's educational attainment" had three other significant associations which lost significance when adjusted.

Having "no previous preterm baby born in the household" was associated with a lesser likelihood of "experiencing economic sacrifice due to the care of the current baby" (OR: 0.32; CI: 0.12-0.87; $P=0.03$ ) and "a feeling that life has been unfair" (OR: 0.19; CI: $0.05-0.77 ; P=0.02$ ). However, after adjustment, only the "feeling that life has been unfair" (OR: 0.23; CI: $0.05-0.99 ; P=0.05)$ remained significant.

Similarly, caregivers of sick newborns who stayed 7 days or less in hospital were less likely to face practical problems in the care of baby that may be difficult to solve (OR 0.21; CI 0.07-0.58; $P=0.003$ ) or report that the "physical environment made caring for the baby hard" (OR: 0.28; CI: 0.11-0.69; $P=0.01)$. On adjustment, only the association with "physical environment made caring for the baby hard" remained significant (OR: 0.37; CI: 0.14-0.99; $P=0.05)$.

Family sizes also had significant associations with caregiver burdens. Families with just one or no other child were almost three times more likely to report that "physical environment made caring for the baby hard" remained significant (OR: 2.90; CI: 1.08-7.77; 
Table 3: Two-stage regression analyses of factors affecting psychosocial burdens of caregivers to sick babies in the Newborn Unit of Enugu State University Teaching Hospital $(n=134)$

\begin{tabular}{|c|c|c|c|c|c|}
\hline \multicolumn{2}{|r|}{ Variables } & \multicolumn{2}{|l|}{ Crude } & \multicolumn{2}{|l|}{ Adjusted } \\
\hline Dependent & Independent & OR $(95 \% \mathrm{CI})$ & $P$ & OR $(95 \% \mathrm{CI})$ & $P$ \\
\hline \multirow{4}{*}{$\begin{array}{l}\text { Place of birth } \\
\text { (inborn vs. outborn) }\end{array}$} & Feels offended and angry with the baby's health condition? & $0.29(0.12-0.71)$ & $0.01 *$ & $0.24(0.04-1.36)$ & 0.11 \\
\hline & Feel tied down by baby's problem? & $0.31(0.11-0.82)$ & $0.02 *$ & $0.56(0.20-1.57)$ & 0.27 \\
\hline & Baby's problem prevented own ambitions? & $0.30(0.13-0.70)$ & $0.01 *$ & $0.61(0.19-1.94)$ & 0.40 \\
\hline & Feeling that life has been unfair due to having the baby? & $0.19(0.04-0.93)$ & $0.04 *$ & $0.37(0.14-0.98)$ & $0.05^{*}$ \\
\hline \multirow[t]{4}{*}{ Father's HEL** } & $\begin{array}{l}\text { Facing problems in the care of baby that may be difficult } \\
\text { to solve? }\end{array}$ & $0.30(0.10-0.95)$ & $0.04 *$ & $0.71(0.18-2.90)$ & 0.64 \\
\hline & Baby's problem prevented own ambitions? & $0.31(0.10-0.91)$ & $0.03 *$ & $0.43(0.12-1.48)$ & 0.18 \\
\hline & Worry about not properly caring for the baby? & $0.19(0.06-0.64)$ & $0.01 *$ & $0.21(0.06-0.78)$ & $0.02 *$ \\
\hline & Finds it mentally tiring to take care of the baby? & $0.23(0.06-0.91)$ & $0.04 *$ & $0.25(0.05-1.15)$ & 0.07 \\
\hline Mother's HEL** & Worry about not properly caring for the baby? & $0.12(0.03-0.45)$ & $0.001 *$ & $0.12(0.03-0.45)$ & $0.001 *$ \\
\hline \multirow{2}{*}{$\begin{array}{l}\text { Previous preterm } \\
\text { baby? (no vs. yes) }\end{array}$} & Experienced economic sacrifice because of baby care? & $0.32(0.12-0.87)$ & $0.03 *$ & $0.37(0.13-1.04)$ & 0.06 \\
\hline & Feeling that life has been unfair due to having the baby? & $0.19(0.05-0.77)$ & $0.02 *$ & $0.23(0.05-0.99)$ & $0.05^{*}$ \\
\hline $\begin{array}{l}\text { Length stay } \\
\text { in hospital }\end{array}$ & $\begin{array}{l}\text { Facing problems in the care of baby that may be difficult } \\
\text { to solve? }\end{array}$ & $0.21(0.07-0.58)$ & $0.03 *$ & $0.38(0.12-1.18)$ & 0.09 \\
\hline ( $\leq 7$ days vs. $>7$ days) & Physical environment makes caring for the baby hard? & $0.28(0.11-0.69)$ & $0.01 *$ & $0.37(0.14-0.99)$ & $0.05^{*}$ \\
\hline $\begin{array}{l}\text { Number of } \\
\text { children }(\leq 1 \text { vs. }>1)\end{array}$ & Physical environment makes caring for the baby hard? & $2.90(1.08-7.77)$ & $0.03 *$ & $2.90(1.08-7.77)$ & $0.03 *$ \\
\hline $\begin{array}{l}\text { Number of people in } \\
\text { family ( } \leq 3 \text { vs. }>3)\end{array}$ & $\begin{array}{l}\text { Feels embarrassed by the baby's health status or } \\
\text { size/weight? }\end{array}$ & $2.75(1.05-7.20)$ & $0.04 *$ & $2.75(1.05-7.20)$ & $0.04 *$ \\
\hline Birth weight $(\leq 2.49$ & Feels offended and angry with the baby's health condition? & $0.21(0.06-0.75)$ & $0.02 *$ & $0.12(0.02-0.56)$ & $0.01 *$ \\
\hline kg vs. $\geq 2.50 \mathrm{~kg})$ & Feeling that life has been unfair due to having the baby? & $4.54(1.02-20.2)$ & $0.05 *$ & $11.21(1.66-75.8)$ & $0.01 *$ \\
\hline
\end{tabular}

*Statistically significant; **HEL ( $\geq$ SSCE vs. $<$ SSCE). Only results with $P \leq 0.05$ are shown for the nonadjusted results; Only in cases where $>1$ variable has significant $P$ values in the "Nonadjusted column" were included in the "Adjusted" analyses. These include numbers 1, 2, 4, 5, and 8; All cases in the "Nonadjusted" columns with only one significant variable required no "Adjustment" and were carried over the "Adjusted" column. These include numbers 3, 6, and 7. HEL - Highest educational level; SSCE - Senior secondary school certificate examination; OR - Odds ratio; CI - Confidence interval

$P=0.03$ ), whereas those with three or less other individuals (including adults) in the household were more likely to report "a feeling of embarrassment the baby's health status or size/weight" (OR: 2.75; CI: 1.05-7.20; $P=0.04)$.

The final sets of significant associations were found with the birth weights of the babies. Caregivers to underweight babies $\leq 2.49 \mathrm{~kg}$ were less likely to "feel offended and angry with the baby's health condition" (OR: 0.21; CI: $0.06-0.75 ; P=0.02$ ), but more likely to feel that "life has been unfair because of the baby" (OR: 4.54; CI: $1.02-20.21 ; P=0.05)$. These two findings remained statistically significant after adjustment.

It should be noted that six other dependent variables revealed no significant associations with any of the 22 parameters of caregiver burdens. These include "gender," "mother's employment status," "disability in another baby," "special support received while baby was on admission," and having a large family ("either by more than 3 other children" or " 5 or more other individuals in the household").

\section{Discussion}

The survival of a newborn is dependent on the care received. ${ }^{[4]}$ Care is provided for sick newborns by both health-care workers and the parents/caregivers. Extensive work has been done in developing countries about the challenges faced by health-care workers. ${ }^{[5,6]}$ Psychosocial risks, which include poor socioeconomic conditions such as poverty and lack of social support affecting caregivers, have been identified as contributing to high infant mortality. ${ }^{[7,8]}$ We hypothesized that all these psychosocial stressors constitute a burden on caregivers and appropriate interventions are required to promote optimal development of newborns.

Majority of the respondents in the present study were males in an area of newborn care that is often seen as dominated exclusively by females. This finding may be because men generally take leadership in Nigerian families, and when invited to respond to this survey, the women are likely to leave it to the men to complete the survey, even when the women were the primary caregivers. This notwithstanding, empirical research confirms that with higher levels of education, as reflected in our study and planned pregnancies, men are more likely to be involved in newborn-related care. ${ }^{[9,10]}$ There 
are increased calls to facilitate this transition away from newborn health being viewed as an exclusively female domain. ${ }^{[9]}$ Interventions to increase male involvement in newborn care include addressing hospital policies and staff attitudes in facilities to allow for culturally sensitive, inclusive policies for men and families, such as special visiting hours and supporting fathers to participate in KMC..$^{[1]}$

It is interesting to observe that none of the parameters that captured the caregiver burdens were up to $50 \%$, with the majority being quite low. This may be a consequence of the fact that most of them attended antenatal care which involves screening symptomatic and asymptomatic pregnant women, with the aim of detecting and thereby preventing both maternal and neonatal adverse events. ${ }^{[8]}$ When effectively administered, antenatal care promotes health and prevents physical and psychosocial problems. ${ }^{[12]}$ Given this, we recommend that health practitioners should endeavor to encourage more women to deliver their babies in tertiary centers, particularly if admissions to newborn units are anticipated postdelivery. In addition, the extended family system may play a role in reducing psychosocial burdens on caregivers. Families are integrated into decision-making processes in their baby's care as family-centered developmental care recognizes the family as vital contributors to the health-care team. ${ }^{[13]}$

Notwithstanding the reduced reports, the highest burdens were reported as "an experience of economic sacrifice because of baby," "worry about not properly caring for the baby," and "a feeling of loneliness and isolation." Similar findings have been reported by other researchers. ${ }^{[5,14]}$ Koenraads et al. in Southern Malawi reported high burden of care, feeding problems, and discrimination/stigma as burdens for caregivers, stated as: "Taking care of a small baby is a problem. ${ }^{[14]}$ For instance I did not have time to do other work except concentrating on exclusive breastfeeding... though with scarcity of food in the house from morning to evening this life seems tough," "When he was born the breastmilk was not coming out, I tried forcing him to suck, but his jaws were not ready," and "When they see us they point fingers at us..." It should stand to reason that these reported burdensome experiences could worsen when dealing with a sick baby in a hospital setting. One major surprise was that the provision of support (financial or otherwise) was not associated with alleviation in the caregiver burden. The reason for this may be related to the fact that these donations were largely one-offs, but the issues that created the burdens were deeper and largely ongoing.
It is no surprise that the caregivers of babies born within the ESUTH Teaching Hospital reported less burdens on multiple aspects compared to those born outside ESUTH. Such caregivers may have attended antenatal care in ESUTH and received prenatal counseling which has boosted their psychosocial adaptation. Hence, they are also more familiar with the terrain and modus operandi of the hospital setting and would easily access the requested items for the care of their babies without much stress. On this premise, the authors strongly recommend that women should be encouraged to deliver their babies in tertiary centers, particularly if admissions to newborn units are anticipated postdelivery.

Special attention should be paid to parents who have had previous preterm-babies and then have another baby in the newborn unit. This is necessary given the findings that they are more likely to face higher burdens. Even though parents of children with other disabilities are expected to face similar burdens, ${ }^{[15]}$ this was not found to be so by this study. This observation might be explained by the low numbers of disabled cases, with only three respondents reporting having another disabled child in their families. As such, the numbers are not robust enough to make a reasonable conclusion in this regard.

It is not clear why small families, either with one other child or with three other family members in total, tend to report higher burdens with the "physical environment made caring for the baby hard" and an "embarrassment the baby's health status," respectively. A family of just one other child, whose newest baby is in a care unit, is likely to have the older child as a toddler. This will probably make it more difficult to care for the new baby, as the toddler may not be easily contained in the limited space that the baby units can provide. In view of this, the burdens on parents may be made easier if facilities for caring for toddlers or younger children can be made available in these hospitals. This can then be used by the families involved, thereby limiting this burden. The finding on lager families may be better understood with future studies.

Caregivers to low-birth weight babies $\leq 2.49 \mathrm{~kg}$ were less likely to "feel offended and angry with the baby's health condition," but more likely to feel that "life has been unfair because of the baby." These two findings remained statistically significant after adjustment. A typical Nigerian in the study environment believes that a child especially the newborn is innocent of whatever health condition that may befall it, rather any unfavorable condition should blame on nature and God. This may explain why they do not easily get offended with the baby's health condition. 
During childbirth, even the working mothers are officially given 4 months maternity leave in Nigeria to allow them to take care of their baby. This development tends to minimize work/childcare conflict in the immediate newborn period, hence explaining the nonsignificant association of caregivers' burden with the mother's employment status. Furthermore, no newborn care indices in the form of drugs, length of hospital stay, term or preterm, or birth weight is dependent on the gender of the newborn, thus explaining the nonsignificant association of burden of care with the gender of the newborn.

The association of parental level of education and levels of burden was equally not surprising. This may be because education helps individuals balance reasoning and can help them confront realities when faced with burdens. A study by the Center of Disease Control and Prevention (CDC) found that the more education one had, the more likely it is that you will live a healthier life. ${ }^{[16]}$ This may lead to less worries (as identified in this study), which can ultimately lead to less burden. Given this, education to at least SSCE should be encouraged for all adults, as this seems to be associated with less experiences of burdens when faced with newborn admissions.

The birth of an infant that needs hospital admission can be stressful for the parents. ${ }^{[17,18]}$ In the present study, caregivers of newborns admitted for 7 days or less were less likely to face increased burdens. This is consistent with the findings of a study done in the United Kingdom in 2010, which demonstrated that the longer the baby is hospitalized, the higher the level of stress, especially for fathers. Hospitals should also aim to shorten the stay of sick newborns as much as possible.

Finally, it is important for health professionals who care for newborns to be aware of these sources of stress and implement strategies to minimize the burden on caregivers.

\section{CONCLUSion}

Caregivers of sick newborn experience significant levels of stressors with implications on the care and outcome of those children. Comprehensive sick newborn care should envisage and incorporate management of different domains of stressors among caregivers. Hospitals caring for sick newborns should incorporate comfortable, well-structured, and adapted under-5 bays where toddler children of the caregivers can be taken care of by trained personnel. Such toddler bays should be close enough to allow unlimited caregivers' oversight. Given the great involvement of fathers in the direct care of these sick newborns, the need for official paternity leave has become even more expedient and urgent. Parental education was shown to be a strong influencer and modifier of stress experience. Having a policy that promotes access to at least secondary education will be quite helpful.

\section{Financial support and sponsorship}

Nil.

\section{Conflicts of interest}

There are no conflicts of interest.

\section{REFERENCES}

1. Neonatal Mortality - UNICEF DATA; 2018. Available from: https://data.unicef.org/topic/child-survival/ neonatal-mortality. [Last accessed on 2019 Jul 26].

2. World Health Organization. World Health Report 2005: Make Every Mother and Child Count. Geneva: World Health Organization; 2005.

3. Ekwochi U, Osuorah DC, Ndu IK, Ezenwosu OU, Amadi OF, Nwokoye IC, et al. Out-of-pocket cost of managing sick newborns in Enugu, southeast Nigeria. Clinicoecon Outcomes Res 2014;6:29-35.

4. Yinger NV, Ransom EL. Why Invest in Newborn Health? Policy Perception on Newborn Health. Washington: Save the Children; 2003.

5. Martinez AM, Khu DT, Boo NY, Neou L, Saysanasongkham B, Partridge JC. Barriers to neonatal care in developing countries: Parents' and providers' perceptions. J Paediatr Child Health 2012;48:852-8.

6. Walker SP, Wachs TD, Grantham-McGregor S, Black MM, Nelson CA, Huffman SL, et al. Inequality in early childhood: Risk and protective factors for early child development. Lancet 2011;378:1325-38.

7. Disu EA. Challenges of Neonatal Care in Nigeria: What Solutions for Child survival. Ikeja, Lagos: Consultant Paediatrician, Lagos State University Teaching Hospital; 2013.

8. Mathibe-Neke JM, Masitenyane SS. Psychosocial Antenatal Care: A Midwifery Context. In: Selected Topics in Midwifery Care. London, United Kingdom: IntechOpen 2018.

9. Moxon SG, Lawn JE, Dickson KE, Simen-Kapeu A, Gupta G, Deorari A, et al. Inpatient care of small and sick newborns: A multi-country analysis of health system bottlenecks and potential solutions. BMC Pregnancy Childbirth 2015;15 Suppl 2:S7.

10. Olayemi O, Bello FA, Aimakhu CO, Obajimi GO, Adekunle AO. Male participation in pregnancy and delivery in Nigeria: A survey of antenatal attendees. J Biosoc Sci 2009;41:493-503.

11. Vesel L, Bergh AM, Kerber KJ, Valsangkar B, Mazia G, Moxon SG, et al. Kangaroo mother care: A multi-country analysis of health system bottlenecks and potential solutions. BMC Pregnancy Childbirth 2015;15 Suppl 2:S5 .

12. Stahl K, Hundley V. Risk and risk assessment in pregnancy - Do we scare because we care? Midwifery 2003;19:298-309.

13. Craig JW, Glick C, Phillips R, Hall SL, Smith J, Browne J. Recommendations for involving the family in developmental care of the NICU baby. J Perinatol 2015;35 Suppl 1:S5-8.

14. Koenraads M, Phuka J, Maleta K, Theobald S, Gladstone M. Understanding the challenges to caring for low birthweight babies in rural Southern Malawi: A qualitative study exploring caregiver and health worker perceptions and experiences. BMJ 
Glob Health 2017;2:e000301.

15. Oh H, Lee EK. Caregiver burden and social support among mothers raising children with developmental disabilities in South Korea. Int J Disab Dev Educ 2009;56:149-67.

16. Centers for Disease Control and Prevention. Health, United States is an annual report on trends in health statistics 2018. Available from: $\mathrm{CDC} /$ National Center for Health Statistics/Division of
Analysis and Epidemiology. [Last assessed on 2019 Nov 29].

17. Stübe $M$, da Rosa MB, Pretto CR, da Cruz CT, Vione $P$, Morin EM. Stress levels of newborns parents in neonatal intensive care unit. Northeast Netw Nurs J 2018;19:e3254.

18. Harvey ME. The experiences and perceptions of fathers attending the birth and immediate care of their baby. Birmingham, UK: Aston University; 2010. 